\title{
3-Methyltrimethylammonium poly(2,6-dimethyl-1,4-phenylene oxide) based anion exchange membrane for alkaline polymer electrolyte fuel cells
}

\author{
K HARI GOPI, S GOUSE PEERA, S D BHAT*, P SRIDHAR and S PITCHUMANI \\ CSIR-Central Electrochemical Research Institute-Madras Unit, CSIR Madras Complex, Chennai 600 113, India
}

MS received 2 May 2013; revised 13 May 2013

\begin{abstract}
Hydroxyl ion $\left(\mathrm{OH}^{-}\right)$conducting anion exchange membranes based on modified poly (phenylene oxide) are fabricated for their application in alkaline polymer electrolyte fuel cells (APEFCs). In the present study, chloromethylation of poly(phenylene oxide) (PPO) is performed by aryl substitution rather than benzyl substitution and homogeneously quaternized to form an anion exchange membrane (AEM). ${ }^{1} \mathrm{H}$ NMR and FTIR studies reveal successful incorporation of the above groups in the polymer backbone. The membrane is characterized for its ion exchange capacity and water uptake. The membrane formed by these processes show good ionic conductivity and when used in fuel cell exhibited an enhanced performance in comparison with the state-of-the-art commercial AHA membrane. A peak power density of $111 \mathrm{~mW} / \mathrm{cm}^{2}$ at a load current density of $250 \mathrm{~mA} / \mathrm{cm}^{2}$ is obtained for PPO based membrane in APEFCs at $30{ }^{\circ} \mathrm{C}$.
\end{abstract}

Keywords. Alkaline polymer electrolyte fuel cell; anion exchange membrane; PPO; homogeneous quaternization.

\section{Introduction}

Presently, alkaline polymer electrolyte fuel cells (APEFCs) using anion exchange membranes have received an immense interest among researchers (Varcoe and Slade 2005). The advantages of APEFCs lie in their low activation loss, fast cathode kinetics that permits the use of non-precious metal catalysts (Lin et al 2006) and reduced oxidant reduction over-potential at high $\mathrm{pH}$ with increased efficiency (Gu et al 2009). Issues in alkaline fuel cells (AFCs) are the formation of carbonate salts when $\mathrm{KOH}$ or $\mathrm{NaOH}$ solution reacts with $\mathrm{CO}_{2}$ at the cathode (McLean et al 2002) and the $\mathrm{pH}$ change in the catalyst region due to carbonation causing voltage loss (Wang et al 2003). These problems are addressed by the use of solid electrolyte in APEFCs.

Recently, there have been several attempts to develop solid polymer electrolytes (SPE) for alkaline fuel cell (Merle et al 2011). Earlier reports on anion exchange membrane (AEM) focused on using polymers like polyvinyl alcohol (PVA) and poly(ethylene oxide) (PEO) as solid support to hold alkaline solution for its $\mathrm{OH}^{-}$conductivity (Wu et al 2008; Xiong et al 2008;). SPE comprising conducting polymers are the polyelectrolytes which have ionic sites (usually quaternary ammonium or quaternary phosphonium type) grafted on the polymer backbone. To

*Author for correspondence (sdbhatcecri@gmail.com) preserve the polymer electroneutrality, a mobile counter-ion is attached to each ionic functional group (Agel et al 2001).

Many studies have been devoted to develop quaternized polymers by introducing reactive chloromethyl group followed by its reaction with tertiary phosphine, tertiary amine and pentamethylguanidine (Li et al 2006; Wang J et al 2010; Arges et al 2012). Several AEMs were prepared using the aromatic moiety of a variety of polymers like poly(ether-imide) (PEI), polysulfone (PS), poly (arylene ether sulfone) (PESF), etc (Fang and Shen 2006; Zhou et al 2009; Yan and Hickner 2010; Wang G et al 2010). Also Varcoe and Slade (2006) prepared AEMs by radiation grafting of monomers onto the polymer films using $\gamma$-ray source.

Poly(phenylene oxide) (PPO) has emerged as one of the most promising polymer for the fabrication of anion exchange membrane due to its excellent physicochemical properties. Wu et al (2010) prepared AEMs by incorporating silica into $\mathrm{PPO}$ which exhibited high tensile strength and good conductivity. Recently, membranes with imidazolium groups (attached to benzyl position) have been developed from brominated PPO (BPPO) with good ionic conductivities (Ran et al 2012). But imidazolium cation is not advantageous over the benchmark quaternary ammonium cation due to its poor stability (Deavin et al 2012). The present study reports the introduction of quaternary ammonium cation on the aryl carbon rather than benzyl carbon in the preparation of anion exchange membrane from engineering plastics, viz. 
poly(2,6-dimethyl-1,4-phenylene oxide) via chloromethylation followed by a pre-functionalization methodology for quaternization.

\section{Experimental}

\subsection{Chloromethylation of PPO}

The chloromethylation of poly(2,6-dimethyl-1,4-phenylene oxide) (PPO) was carried out as reported in the literature (Wang et al 2010). Required amount of PPO was dissolved in chlorobenzene (15 wt\% solution) in a three-neck roundbottom flask equipped with reflux condenser and a mechanical stirrer. Calculated amount of zinc chloride catalyst with respect to the weight of polymer was dissolved in chloromethyl ethyl ether (twice the molar quantity of the polymer) and then added drop-wise into the flask containing PPO solution. The reaction mixture was allowed to stir for $5 \mathrm{~h}$ at $50{ }^{\circ} \mathrm{C}$ under reflux condition. After cooling, the mixture was precipitated using methanol, washed with distilled water and dried in an oven at $70{ }^{\circ} \mathrm{C}$ for $24 \mathrm{~h}$ to form whitish-chloromethylated PPO (CPPO).

\subsection{Membrane fabrication}

Anion exchange membrane was formed by quaternization through homogeneous amination. Homogeneous amination was carried out by dissolving the dried CPPO in 1methyl-2-pyrrolidone (NMP) to prepare $3 \mathrm{wt} \%$ solution. To this, trimethylamine solution (30 wt\% in water) was added and the reaction mixture was stirred for $24 \mathrm{~h}$ at room temperature. The solution was poured onto a flat glass plate and dried at $75^{\circ} \mathrm{C}$ in a vacuum oven to form QPPO membrane. The obtained membrane was soaked in $2 \mathrm{~mol} \mathrm{~L}^{-1} \mathrm{KOH}$ solution for $24 \mathrm{~h}$ to convert from chloride to hydroxide form. Finally, the membrane was repeatedly washed with deionized water to remove residual $\mathrm{KOH}$ and stored in deionized water prior to use.

\subsection{Structural characterization}

Proton $\left({ }^{1} \mathrm{H}\right)$ NMR spectra were recorded on a Bruker instrument at $300 \mathrm{MHz}$ using deuterated chloroform $\left(\mathrm{CDCl}_{3}\right)$ as the solvent and tetramethylsilane as an internal standard. The chemical modification of the polymers was further confirmed by Fourier transform infrared spectrophotometer (FT-IR-ATR) (Thermo Electron Corporation, Model Nexus 670) within the spectral range of $4000-400 \mathrm{~cm}^{-1}$.

\subsection{Ion exchange capacity, water uptake and ionic conductivity}

Ion exchange capacity (IEC, in $\mathrm{mmol} / \mathrm{g}$ ) was determined using the Mohr's titration method (Li et al 2006). Water uptake measurements were carried out by sorption method (Mohanapriya et al 2009). The conductivity of the membranes was measured using a two-probe a.c. impedance spectroscopy with AUTOLAB PGSTAT 30 over the frequency range from $1 \mathrm{MHz}$ to $10 \mathrm{~Hz}$ with $10 \mathrm{mV}$ amplitude at varying temperatures ranging from 30 to $70{ }^{\circ} \mathrm{C}$ as reported earlier in the literature (Mohanapriya et al 2009). Before testing, the membranes were equilibrated in deionized water for $24 \mathrm{~h}$.

\subsection{Membrane-electrode assembly (MEA) fabrication and APEFC performance evaluation}

Teflonized Toray-TGP-H-120 carbon papers were coated with the slurry of Vulcan XC-72R carbon suspended in cyclohexane along with $15 \mathrm{wt} \%$ polytetrafluroethylene (PTFE) to form the gas diffusion layer. The catalyst ink was prepared by taking the required amount of $40 \% \mathrm{Pt} / \mathrm{C}$ in deionized water followed by the addition of ethanol solution containing Fumion (FAA-3) ionomer and ultrasonication for $30 \mathrm{~min}$. The electrodes (both anode and cathode) were prepared by coating the catalyst ink on the gas diffusion layer until the desired Pt loading of $0.5 \mathrm{mg} /$ $\mathrm{cm}^{2}$ was reached. The electrodes were dipped in $\mathrm{KOH}$ solution $\left(1 \mathrm{~mol} \mathrm{~L}^{-1}\right)$ to exchange the binder from $\mathrm{Cl}^{-}$to $\mathrm{OH}^{-}$form. MEA was formed by sandwiching QPPO membrane between the above two electrodes and then placed in a single-cell fixture with parallel serpentine flow-field machined on graphite plates. The active electrode area was $4 \mathrm{~cm}^{2}$ with humidified $\mathrm{H}_{2}$ and $\mathrm{O}_{2}$ flowing at $200 \mathrm{~mL} \mathrm{~min}^{-1}$. Cell polarization studies were carried out galvanostatically using electronic load Model-LCN425-24/LCN 50-24 from Bitrode Instruments (US).

\section{Results and discussion}

The preparation of anion exchange membrane (AEMs) involves chemical reactions such as chloromethylation and quaternization followed by ion exchange. Among them, chloromethylation and quaternization are the two key reactions that influence the conductivity. Chloromethylation is the crucial step in the synthesis of functionalized polymers because of its high reactivity that determines the subsequent degree of quaternization, in turn influencing the anion conductivity. In the present study, chloromethylation is done on the aromatic ring of the polymer making it less susceptible to steric hindrance unlike the conventional method of benzyl substitution wherein the electronegative nature of oxygen presumably tend to withdraw electrons towards itself thus, reducing the electropositive character of nitrogen. Chloromethylated PPO was further quaternized by homogeneous amination, in which PPO is directly converted to ionic form and is equally distributed over the polymer matrix because of strong ionic interactions when compared with 
heterogeneous amination (Yan and Hickner 2010). Scheme 1 provides synthetic protocol for the preparation of alkaline membrane from PPO.

\subsection{NMR and FT-IR studies}

The chloromethylation reaction was confirmed by ${ }^{1} \mathrm{H}$ NMR spectra. Figure 1 shows proton resonance signals of both PPO and chloromethylated PPO (CPPO). The peak at $6 \cdot 4-6.5 \mathrm{ppm}$ is assigned to the aryl protons of PPO.
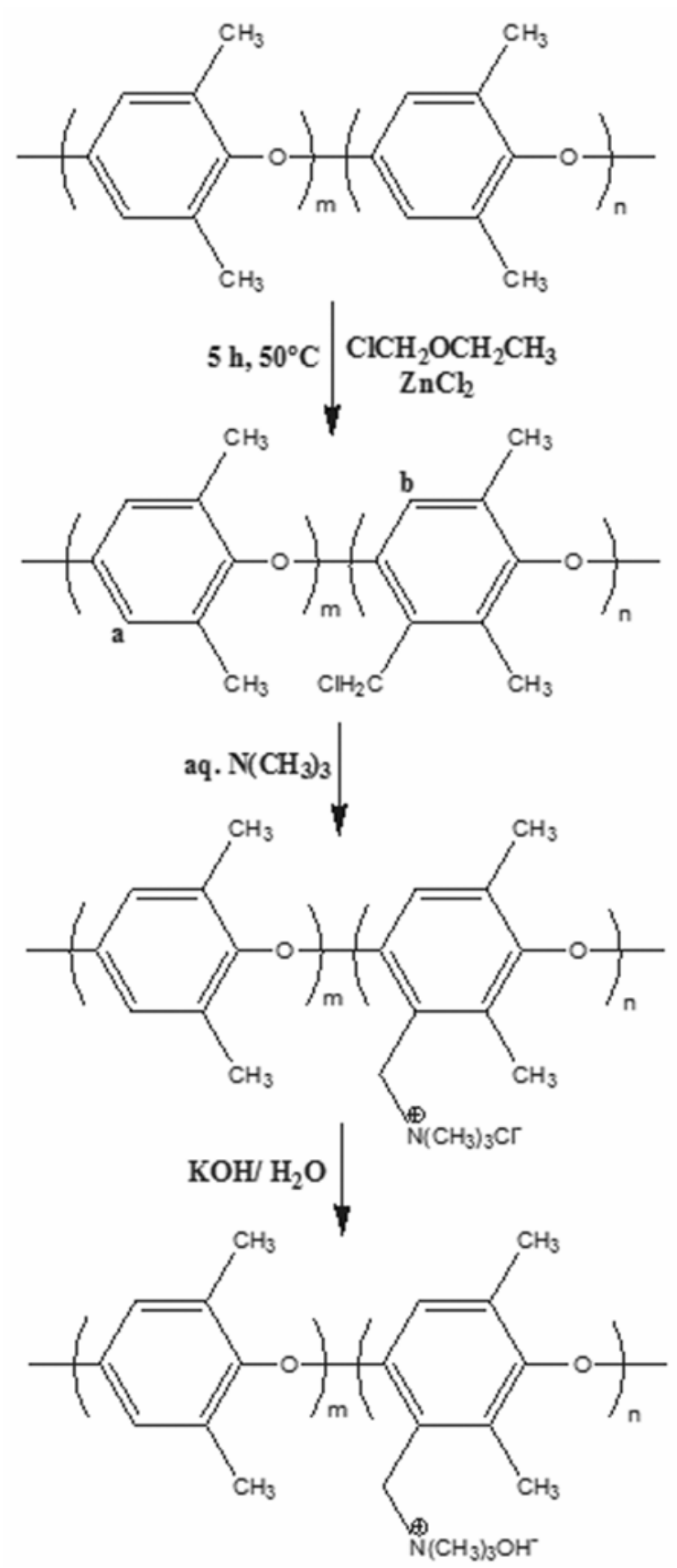

Scheme 1. Synthetic procedure for preparation of quaternized PPO membrane.
The protons due to the benzyl group appear at 2.0$2 \cdot 1 \mathrm{ppm}$ as a multiplet. Two prominent peaks appear in the spectra of CPPO. The peak at $4.9 \mathrm{ppm}$ is attributed to the protons of chloromethyl group, and because of electrophilic substitution, aryl protons are shifted to a new position at $6.1 \mathrm{ppm}$. The percentage of substitution of chloromethyl group was calculated using the following relation (Wu et al 2006):

$$
\text { DS }(\%)=\frac{100 * b}{0 \cdot 5 a+b},
$$

where $a$ and $b$ are the integrals of protons represented in the spectra. The maximum degree of substitution observed for CPPO is represented in table 1.

The chemical structures of the functionalized polymers were further investigated by FT-IR. Figure 2 shows FTIR spectra of PPO, CPPO and QPPO. The peak at $1600 \mathrm{~cm}^{-1}$ corresponds to $\mathrm{C}=\mathrm{C}$ bond stretching and the band at $1190 \mathrm{~cm}^{-1}$ is due to $\mathrm{C}-\mathrm{O}-\mathrm{C}$ stretching (Wu et al 2010) of PPO. In CPPO, the peak at $720 \mathrm{~cm}^{-1}$ is assigned to the stretching vibration of $\mathrm{C}-\mathrm{Cl}$ bond and the band at $1410 \mathrm{~cm}^{-1}$ is the characteristic bending vibration of $\mathrm{CH}_{2}$ group (Lu et al 2008). Since ${ }^{1} \mathrm{H}-\mathrm{NMR}$ spectra were not recorded for QPPO due to its insolubility in $\mathrm{CDCl}_{3}$; the introduction of quaternary ammonium group was confirmed by FT-IR. In QPPO, a new absorption peak at $930 \mathrm{~cm}^{-1}$ due to $\mathrm{C}-\mathrm{N}$ stretching indicates the characteristic peak of quaternary ammonium group (Wu et al 2006). In addition, the absence of peak at $720 \mathrm{~cm}^{-1}$ ( $\mathrm{C}-\mathrm{Cl}$ bond) also confirms conversion of the chloromethyl group to quaternary ammonium group. Also the band at $1410 \mathrm{~cm}^{-1}$ $\left(\mathrm{CH}_{2}\right.$ group) is shifted to a higher wavenumber at $1440 \mathrm{~cm}^{-1}$ due to quaternization.

\subsection{Membrane conductivity and APEFC performance studies}

Ionic conductivity is a vital property that influences the performance of a fuel cell. Membrane conductivity is influenced by ion concentration, ion mobility and level of hydration. Figure 3 represents anionic conductivity of QPPO membrane in comparison with AHA membrane at varying temperatures from 30 to $70{ }^{\circ} \mathrm{C}$. In general, the anion conductivity increases with increase in temperature due to the enhanced mobility of anion. Under fully hydrated conditions, the conductivity of QPPO membrane was in the range of $0.004-0.008 \mathrm{~S} / \mathrm{cm}$. Among the two membranes, QPPO reached a maximum conductivity of $8.3 \times$ $10^{-3} \mathrm{~S} / \mathrm{cm}$ at $70^{\circ} \mathrm{C}$ due to higher IEC and water uptake in comparison with AHA. The ionic conductivity data for QPPO and AHA membranes and its corresponding IEC and water uptake values are shown in table 1 .

Figure 4 shows cell polarization curves for MEAs containing QPPO and commercial AHA membranes at $30{ }^{\circ} \mathrm{C}$. A higher peak power density of $111 \mathrm{~mW} / \mathrm{cm}^{2}$ at a load 

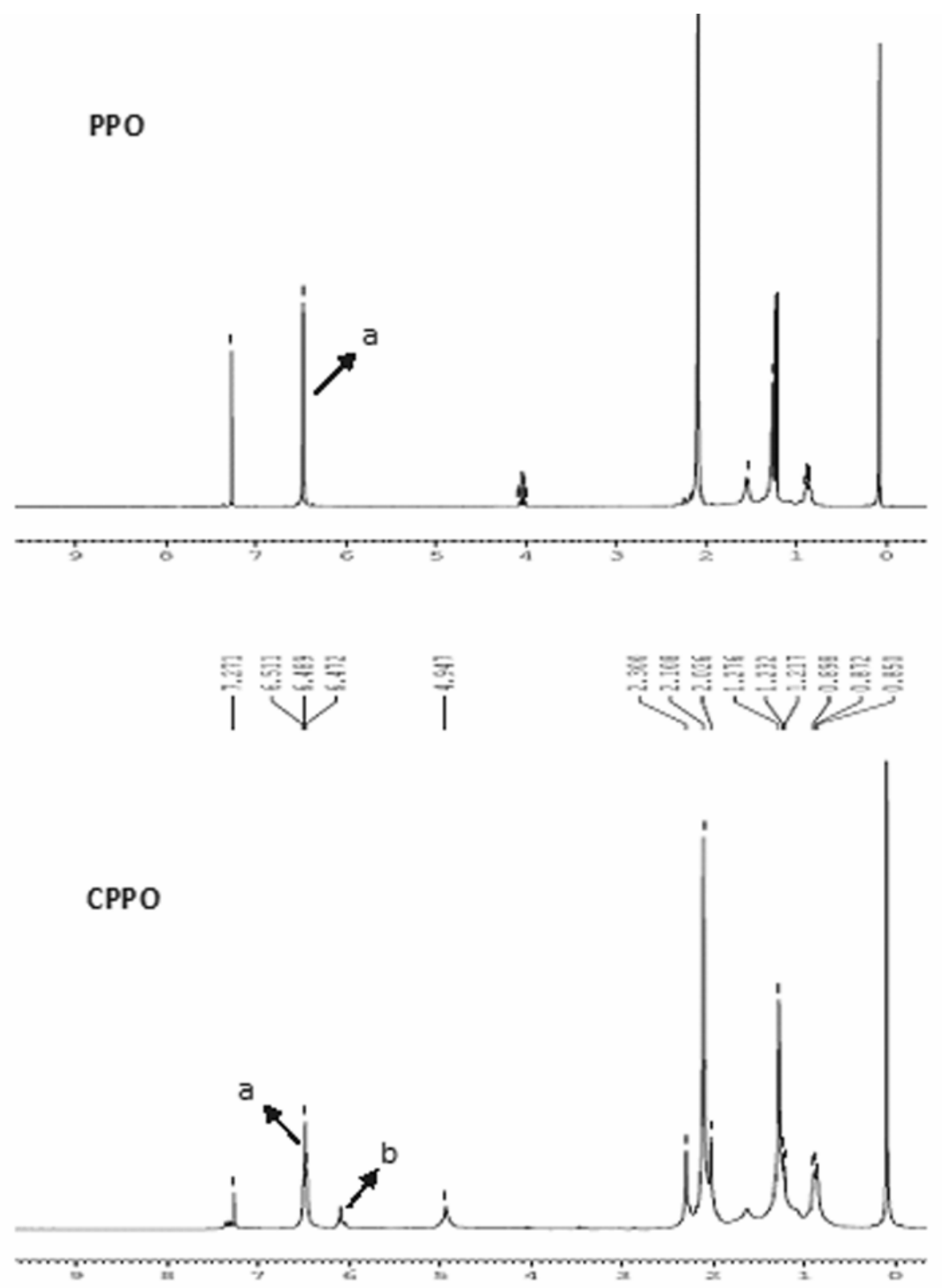

Figure 1. ${ }^{1} \mathrm{H}$ NMR spectra of PPO and CPPO.

Table 1. Characteristic properties of PPO and its membrane.

\begin{tabular}{|c|c|c|c|c|c|c|}
\hline \multirow[b]{2}{*}{ Sample type } & \multirow{2}{*}{$\begin{array}{c}\text { Degree of } \\
\text { substitution }^{\mathrm{a}}(\%)\end{array}$} & \multirow{2}{*}{$\begin{array}{l}\text { Nitrogen content }{ }^{\mathrm{b}} \\
\text { (wt\%) }\end{array}$} & \multicolumn{2}{|c|}{ Conductivity $(\mathrm{mS} / \mathrm{cm})$} & \multirow{2}{*}{$\begin{array}{c}\text { IEC } \\
(\mathrm{mmol} / \mathrm{g})\end{array}$} & \multirow{2}{*}{$\begin{array}{c}\text { Water uptake } \\
(\%)\end{array}$} \\
\hline & & & $30^{\circ} \mathrm{C}$ & $70^{\circ} \mathrm{C}$ & & \\
\hline СРРО & 40 & - & - & - & - & - \\
\hline QPPO membrane & - & $2 \cdot 33$ & $4 \cdot 36$ & $8 \cdot 3$ & $0 \cdot 70$ & 25 \\
\hline AHA membrane & - & - & $1 \cdot 7$ & $2 \cdot 7$ & $0 \cdot 35$ & 15 \\
\hline
\end{tabular}

${ }^{\mathrm{a} C}$ Calculated from NMR spectra. ${ }^{\mathrm{b}}$ Determined from CHNS analysis.

current density of $250 \mathrm{~mA} / \mathrm{cm}^{2}$ is observed for QPPO based MEAs in comparison with a peak power density of $58 \mathrm{~mW} / \mathrm{cm}^{2}$ at a load current density of $125 \mathrm{~mA} / \mathrm{cm}^{2}$ for AHA based MEAs. The higher performance is due to the substitution of chloromethyl groups in aryl position of polymer which increases the distance of interaction between the quaternary ammonium group and oxygen atom of polymer thus inhibiting the steric hindrance. However, 


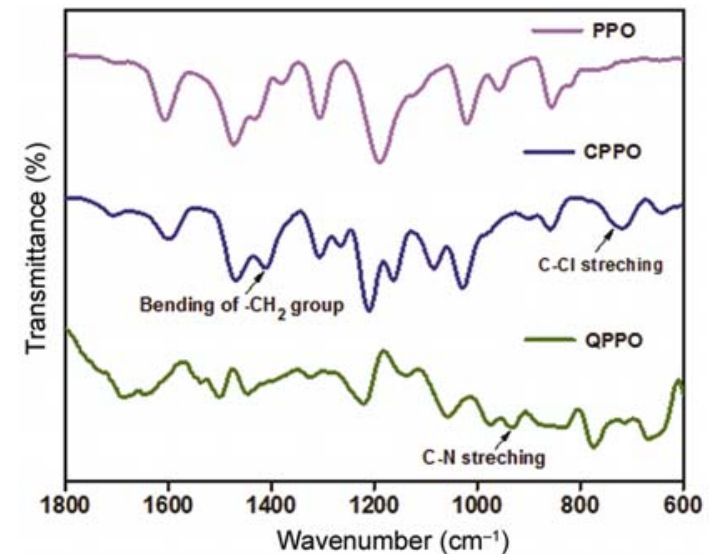

Figure 2. FT-IR spectra of PPO, CPPO and quaternized PPO.

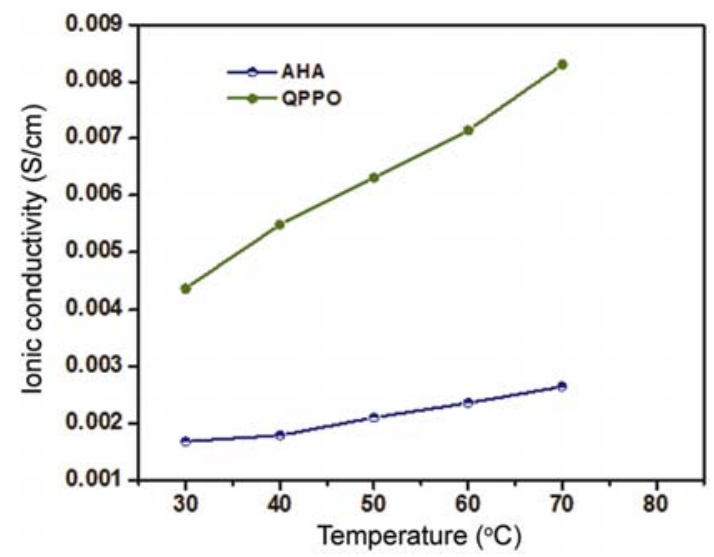

Figure 3. Conductivity for QPPO and AHA membranes as a function of temperature.

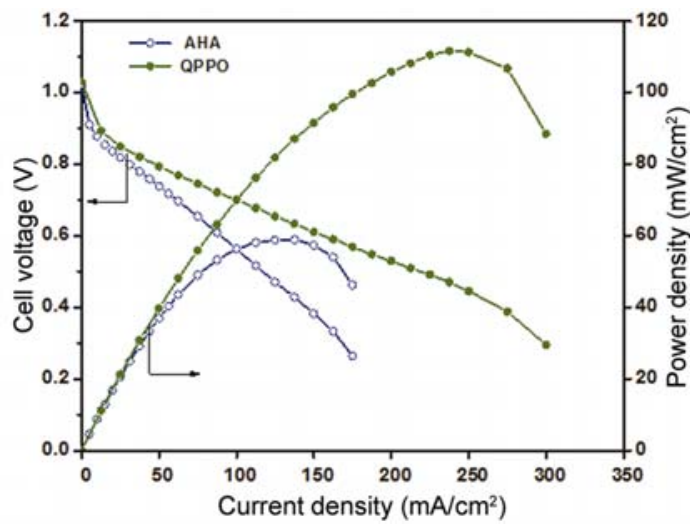

Figure 4. Cell performance curves of APEFCs comprising AHA and QPPO membranes.

at higher temperatures, performance of the membrane decreased probably due to a possible degradation because of nucleophilic attack of $\mathrm{OH}^{-}$on the polymer backbone by $S_{\mathrm{N}} 2$ nucleophilic displacement (Fang and Shen 2006). The above performance needs to be further optimized by varying the ionomer content in the catalyst layer and by improving the membrane stability at higher temperatures. Further studies on these issues are in progress.

\section{Conclusions}

An anion exchange membrane was prepared by chloromethylation and quaternization of PPO. Chloromethylation of aromatic ring and homogeneous quaternization have resulted in the enhanced ionic conductivity of anion exchange membrane. The membrane in alkaline fuel cell showed higher performance in comparison with the commercial AHA membrane.

\section{Acknowledgements}

Authors acknowledge CSIR for financial support under 12th Five Year Plan-HYDEN Programme (CSC 0122). Authors also thank Dr Radhakrishnan, CECRI, Karaikudi, for his help in NMR spectral studies.

\section{References}

Agel E, Bouet J and Fauvarque J F 2001 J. Power Sources 101 267

Arges C G, Parrondo J, Johnson G, Nadhan A and Ramani V 2012 J. Mater. Chem. 223733

Deavin O I, Murphy S, Ong A L, Poynton S D, Zeng R, Herman H and Varcoe J R 2012 Energ. Environ. Sci. 5 8584

Fang J and Shen P K 2006 J. Mem. Sci. 285317

Gu S, Cai R, Luo T, Chen Z, Sun M, Liu Y, He G and Yan Y 2009 Angew. Chem. 486499

Li Y, Xu T and Gong M 2006 J. Membr. Sci. 279200

Lin B Y S, Kirk D W and Thorpe S J 2006 J. Power Sources 161474

Lu C, Gao B, Liu Q and Qi C 2008 Colloid Polym. Sci. 286553

McLean G F, Niet T, Prince-Richard S and Djilali N 2002 Int. J. Hydro. Energ. 27507

Merle G, Wessling M and Nijmeijer K 2011 J. Membr. Sci. 3771

Mohanapriya S, Bhat S D, Sahu A K, Pitchumani S, Sridhar P and Shukla A K 2009 Energ. Environ. Sci. 21210

Ran J, Wu L, Varcoe J R, Ong A L, Poynton S D and Xu T 2012 J. Membr. Sci. 415-416 242

Varcoe J R and Slade R C T 2005 Fuel Cells 5187

Varcoe J R and Slade R C T 2006 Electrochem. Commun. 8839

Wang Y, Li L, Hu L, Zhuang L, Lu J and Xu B 2003 Electrochem. Commun. 5662

Wang J, Li S and Zhang S 2010 Macromolecules 433890

Wang G, Weng Y, Zhao J, Chu D, Xie D and Chen R 2010 Polym. Adv. Technol. 21554

Wu L, Xu T and Yang W 2006 J. Membr. Sci. 286185

Wu Y, Wu C, Yu F, Xu T and Fu Y 2008 J. Membr. Sci. 30728

Wu Y, Wu C, Varcoe J R, Poynton S D, Xu T and Fu Y 2010 J. Power Sources 1953069

Xiong Y, Fang J, Zeng Q H and Liu Q L 2008 J. Membr. Sci. 311319

Yan J and Hickner M 2010 Macromolecules 432349

Zhou J, Unlu M, Vega J A and Kohl P A 2009 J. Power Sources 190285 